\title{
Review \\ Keypoints to a successful Newborn Hearing Screening. Thirty years of experience and innovations.
}

\author{
Jose Miguel Sequi Canet* ${ }^{1}$ and Juan Brines Solanes ${ }^{2}$. \\ 1 Head of Pediatrics Dpt. University Hospital Fco. Borja. Gandía (Spain); sequi_jos@gva.es \\ 2 Honorary Professor of Pediatrics University of Valencia (Spain). juan.brines@uv.es \\ * Correspondence: sequi_jos@gva.es;
}

\begin{abstract}
Congenital deafness is a major pediatric problem, affecting about 1.5-3 per 1000 newborns. The early treatment through cochlear implantation and auditory rehabilitation has been a historic milestone. Early diagnosis of congenital deafness is an essential requirement to obtain the best results, which is achieved through neonatal screening, a diagnostic practice that we began systematically at the Hospital Clínico in Valencia (Spain) 30 years ago.

Neonatal hearing screening is successful in most developed countries. Its implementation has been slow due to the multiple difficulties that its universal application entails since it involves several health professionals and must be carried out,in a short time interval after birth. In addition, it must have a good performance that prevents the overload of other services and that requires experience and continuous adjustments in search of proper protocols.
\end{abstract}

The aim of this review is to shed some light on some key points of neonatal hearing screening, highlighting our experience in the solutions to common problems. We will discuss about techniques, protocols and neonatal or nutritional factors that can influence the screening results.

To a summary of our work, an update on the subject is provided with the intention of sharing experiences and facilitating the start-up of the new units.

Keywords: Neonatal hearing screening; Otoacoustic emissions; Deafness; Newborn screening.

\section{Introduction}

Congenital deafness is a major pediatric problem, affecting about 1-3 per 1000 newborns. Without adequate treatment, its most feared consequence is deaf-muteness. From the mid-Renaissance [1-3] to the end of the 20th century, most children achieved social communication through sign language (Fig 1). 


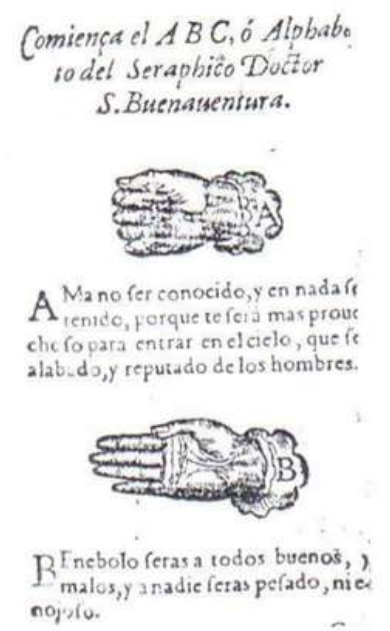

(a)

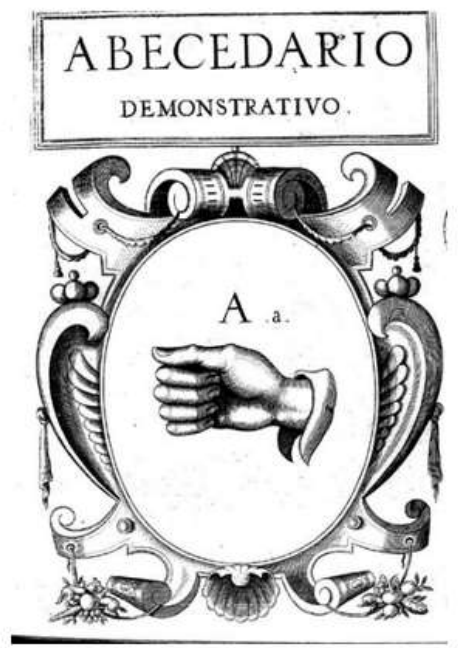

(b)

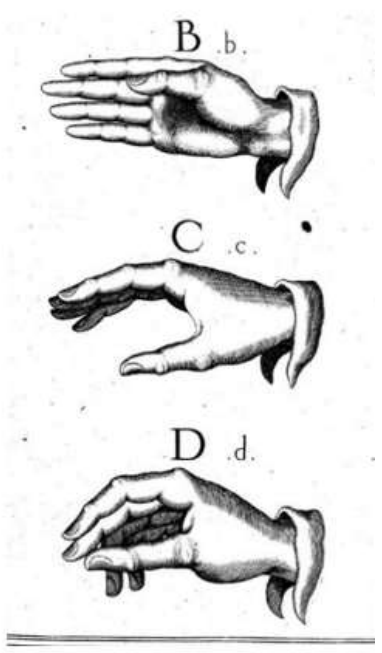

Figure 1. First letters of manual alphabets according to M. de Yebra ( 1593) [1,2] y J.P. Bonet (1620) [3].

The early treatment of these children through auditory rehabilitation programs for learning sound processing and cochlear implantation has been a historic milestone. This fact supports the need for the diagnosis of congenital deafness to be universal and, as soon as possible, that is, through neonatal screening. In this line it is worth remembering that more than $90 \%$ of deaf newborns have healthy parents and that more than $40 \%$ of profoundly deaf require a cochlear implant.

Neonatal hearing screening has been successfully implemented in most Western countries. Its set-up has been slow due to the multiple difficulties that its universal application entails. The organization at a regional level is complex and the technical equipment, preparation of health personnel and administration in general makes it a hard and costly enterprise to run. It involves several care services and levels of health staff; it should be universal and it should be carried out mainly in the short postpartum stay in maternity ward. A good performance is needed to avoid the overload of hospital services concerned. There is currently a strong discussion about the more appropriate technical equipments and protocols to be used, but all the programs manage to increase the early detection of congenital deafness in the neonatal period, which has made it possible to reduce the age of treatment and have better clinical prognosis and psychosocial adaptation.

We have systematically applied this practice at the Hospital Clínico in Valencia (Spain) during the last 30 years [4-6].

This review summarizes our experience over more than three decades and we will discuss the key points to achieve a satisfactory neonatal hearing screening, highlighting the solutions to the problems that usually appear about equipments, techniques, protocols and neonatal or nutritional factors that can influence the results.

\section{Neonatal hearing screening}

Universal neonatal screening is the most useful procedure for early detection of congenital deafness. Neonatal hearing screening facilitates a confirmed diagnosis of neonatal deafness in the first 4 months of life while without this practice the diagnosis is usually delayed up to $35 \mathrm{~m}$. In the same way, the treatment of children diagnosed from neonatal screening begins before $7 \mathrm{~m}$ and in its absence it is delayed on average up to 35 $\mathrm{m}[7-8]$. 
Neonatal hearing screening $(<1$ month) should check both ears and be universal ( $>95 \%$ of newborns). It must be bilateral because unilateral congenital deafness affects neuropsychological development [9].

Under normal conditions if the technical application is adequate, the referral of patients to otorhinolaryngology (ENT) Service will be less than 4\%. Diagnostic confirmation must be done in good conditions before $3 \mathrm{~m}$ and audiologic study before $5 \mathrm{~m}$ in order to begin treatment about $6 \mathrm{~m}$ (Figure 2).

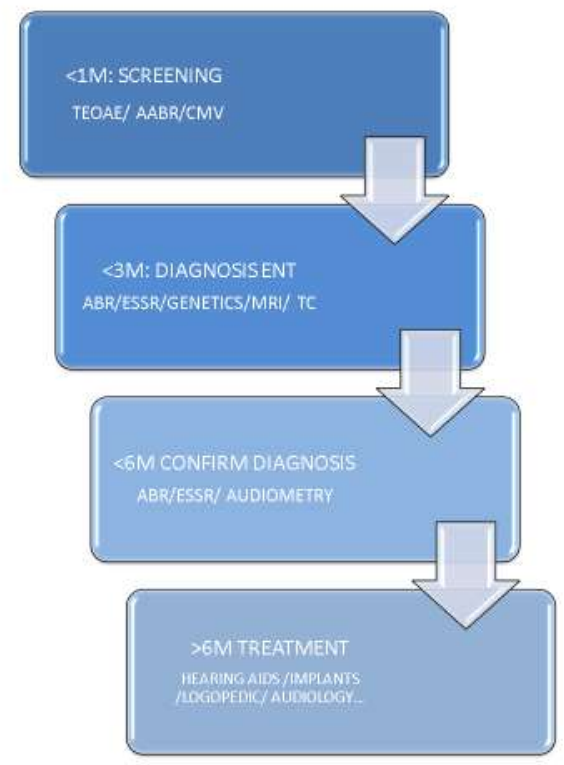

Figure 2. Time goals in hearing screening.

TEOAE: transitory evoked otoacoustic emission; AABR: automated auditory brainstem response, CMV: citomegalovirus; ESSR: steady state potentials; MRI: magnetic resonance, TC: computerized tomography

An universal neonatal screening raises some problems of organization and distribution of tasks related to the responsible hospital service (pediatrics, obstetrics, otorhinolaryngology), health personnel in charge of carrying out the test (pediatrician, nurses, otorhinolaryngologist...), where and when must be done the newborn examination and finally, if the study should be carried out in the presence of the parents. In any case, regular check-ups should be made to ensure that all newborns are examined. Likewise, periodic meetings of the services and staff directly involved (obstetrics, pediatrics and otorhinolaryngology) should be scheduled. In any case, the verbal consent of those responsible for the child is required for legal purposes or a written disclaimer kept in neonatal history if family do not want to do the test.

At the present there is controversy about the technical equipment and protocols to be used, but all the programs reduce the age of treatment achieving a better prognosis for hearing and psychosocial adaptation.

\section{Types of neonatal hearing screening}

When defining the main characteristics of universal neonatal screening for deafness, it must be taken into account that the child will not cooperate and that a large population 
(all neonates) will be included. Consequently, those procedures should be chosen that, like other analytical tests, be sensitive, specific and objective but, given the number of those studied, which are mostly healthy neonates, they must also be atraumatic, simple, repeatable, fast and cheap.

It should be emphasized that screening does not seek a firm diagnosis of the disorder but rather the identification of suspected newborns in order to focus the subsequent effort to its diagnostic confirmation.

Currently, most neonatal hearing screenings are performed with audiological techniques, mainly those based on acoustic otoemissions (Transitory evoked otoacoustic emission, TEOAE) and those based on auditory nerve potentials (Automated auditory brainstem response, $A A B R$ ). Both techniques are sensitive and specific enough to be used in screening but have some differences, the most important of which is the fact that otoemissions only explore hearing up to the cochlear level (which constitutes the most frequent defect with more than $90 \%$ cases) but not the neural pathway, which may be affected in a small proportion of cases. On the other hand, otoemissions are faster and cheaper than AABR and require hardly any consumables. They are also less traumatic since they do not need to put electrodes on the skin and are easier to do. Regarding performance, AABR have fewer false positives than otoemissions, especially in the first days after birth [10-12].

Given that TEOAE do not allow the identification of neural deafness, most authors advise the use of AABR in all children with auditory risk factors due to neural or syndromic pathology.

Discussion persists about the preferred technique in children without risk factors. The sequential use of both techniques in specific cases (first TEOAE and if they fail, AABR later) is gaining followers, which is facilitated by the manageability of the available devices that can do TEOAE and AABR at the same time [13-14].

Currently, more than half of the countries with neonatal hearing screening use TEOAE thanks to its low cost as well as its easy and fast technical implementation, although more programs are increasingly using a mixed protocol (TEOAE-AABR) or, less frequently, only AABR [15-16]

Given the differences in approach on the subject, the Joint Committee on Infant Hearing (JCIH) recommends that each country adopt the most appropriate norms to develop its own protocol in accordance with regional administrative possibilities, government decisions and budget [15]. At the end it depends on the avaibility of time and money because AABR costs 50\% more than TEOAE and needs double of time although it explores neural pathway and has less refers. Consequently, there are professionals who always prefer AABR for a more precise diagnosis and fewer losses in the follow-up of infants.

Concerning the place to carry out the first audiological examination, two alternatives are observed according to local availability of resources, one that conducts the examination at the maternity ward before discharge (assuming more false positives but less losses) and another that prefers to perform the test later in external office (with less false positives and more losses). The former is better done by all nurses and the latter is better done in external office by dedicated staff that filters the referral to ENT. This is recommended also for all retests in babies that fail the first test [17].

It is necessary to monitor the patient in a longitudinal database, accessible to all specialists involved. It reduces the losses in follow-up that are the Achilles heel of the screening programs!

\section{Guides and action algorithms}

Figure 3 shows the algorithnm of newborn hearing screening recommended by the Spanish "Commission for the Early Detection of Hearing Loss" (CODEPEH) [18] 


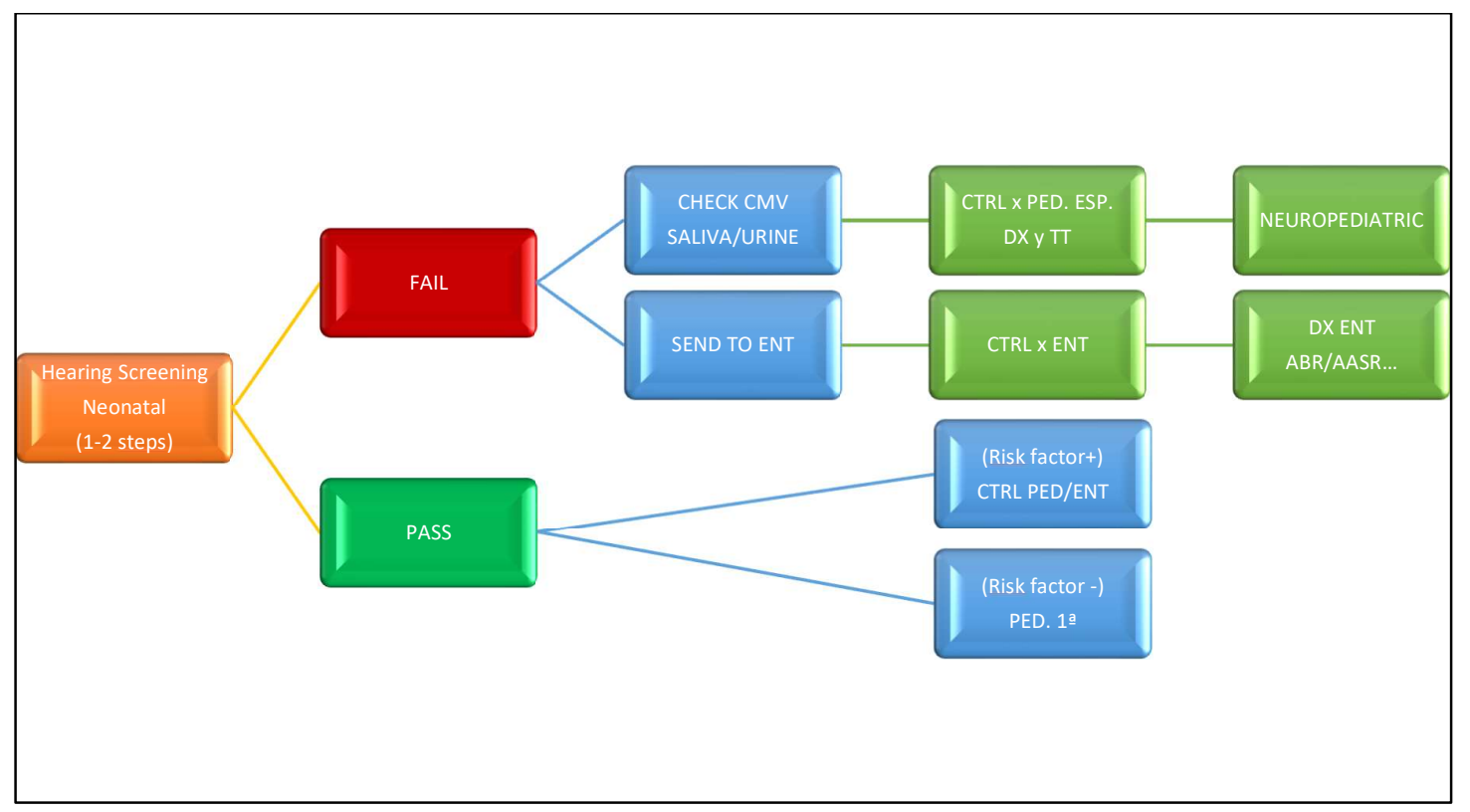

Figure 3. Recommended CODEPEH protocol for newborn hearing screening.

CTRL: control; DX: diagnosis, PED: pediatrics, ENT: otorhinolaryngology; CMV: citomegalovirus

\section{Some details of practical interest in hospital hearing screening.}

There are a series of general and specific aspects that must be taken into account.

1. The test should be performed on all newborns in a quiet room by trained health personnel that also will fill the database with the results.

2. Although the study can be carried out by doctors or nurses, either from the pediatric as well as from the otolaryngology or obstetrics services, due to their location and numerical availability, nurses from obstetrics are the most suitable professionals. If posible it is better that all obstetric nurses are trained in hearing screening because it permits to do the test in all shifts, all day long and covering holidays. Nevertheless in large hospitals one can dedicate a special team of 5 health personnel to do it (it improves reliability but worsens continuity because of holidays and leaves).

3. It is advisable to have two devices available in order not to stop testing if one breaks. For the same reason, two or three probes, eartips and cables must be ready.

4. Do not spend more than 5 minutes on a test. If it is impossible to carry out due to the child's restlessness or other causes, it must be stopped and repeated later. Try to do it after feeding, in a quieter place or using breastfeeding or a pacifier.

5. Do not insist, if a test is a "fail" two times, refer to next level after assuring that the eartip and probe fit, were right and there were no technical problems (too much noise...). On AABR check electrical noise and disconnect as much electronic devices as you can (including mobile phones telephones, pulsioximeters, lights...) and prepare well the skin before in order to diminish the impedances (you can use a special gel).

6. In cases where it is required to repeat the test for failing to pass the first test/step it is important to discuss the inpatient versus outpatient retest issue because the former has more failures (because of middle ear status) but a lower lost to follow-ups; the later has opposing figures. Second test/step must be done by an expert health personnel before 2-3 weeks of age (in order to do a citomegalovirus test if it fails) and controlling the time you are spending, if it fails a pair of tries just send it to ENT.

7. Parents should be informed as soon as possible of the test results. It is very important to explain what results of the screening test mean: the pass means a normal auditory function but refer means only that technique cannot, at that moment, detect a 
normal function and that can be also for technical reasons or lack of aeration of middle ear, so another test must be done in order to confirm the diagnosis some days later. This avoids the excess of anxiety in the family. It is basic to choose the best moment when to communicate results and explain clearly what does the screening test really mean showing the differences of screening versus diagnosis. On the other hand, it is important to remark also the possibility of a late onset hearing loss in spite of a normal screening test. Finally it is necessary to give all information of this issue in a proper cultural competent way offering an appropriate support [19].

In our experience, keeping these considerations in mind, an effective neonatal hearing screening program can be obtained without too many difficulties. With these tips you can do a sustainable local program.

In any case, no matter how detailed and precise the screening is, the lack of follow-up is frequently observed in those newborns who did not pass the examination in the hospital. There is a high percentage of this babies that do not assist to controls or appointments in external office and also some documentation or contact problems. In most programs represent an $8-10 \%$ of the total of retest scheduled. According to Centers of Disease Control (CDC) $45 \%$ of fails detected have an inappropriate global follow-up. These figures are so important that can run down the results of the whole program. In order to solve this issue, it is necessary to have a good coordination between specialist involved with a responsible of program and a very good database with contact data up to date. In the same line it is very useful to have a person that helps the family to navigate between all tests and appointments to be done. It is also basic to have a good collaboration with primary care pediatricians and other health personnel [20].

\section{Additional remarks}

Some additional problems in neonatal hearing screening deserve to be taken into consideration: infection by cytomegalovirus, the type of lactation and the increasing importance of genetic diagnosis.

Cytomegalovirus infection (CMV) reaches a frequency of about $0.5 \%$ of all newborns in developed countries. Most of them are asymptomatic (more than $94 \%$ ) and about 22\% develop either neonatal or late-onset hearing loss.

Approximately $6 \%$ are symptomatic and, of these, 33\%---60\% develop hearing loss. The hearing loss is progressive in 11\%---50\% and late-onset in 5\%---18\% of these children. Early diagnosis is important for considering drug treatment with ganciclovir or valganciclovir, given that several studies have shown their usefulness for improving hearing loss or preventing its progression in these children. For a congenital diagnosis it is necessary to have a positive PCR test in urine before 21 postnatal days and that is the reason for doing retest in hearing screening before this date [21-23].

Breastfeeding is an important factor related to a normal response in TEOAEs test. The reasons are unclear but probably is due to a better middle ear aeration because a more powerful sucking. It may improve the final results of newborn hearing screening reducing the number of neonates who need to be rescheduled for a retest, as well as the associated anxiety and the possibility of losing patients during follow-up. Another good reason to encourage newborn breastfeeding [24-25].

Finally, it is important to highlight the increasing importance of the genetic component in the origins of congenital deafness; a recent research detects genetic abnormalities in up to $80 \%$ of cases including more than 400 known syndromes. In the near future the best option for diagnosis could be a newborn hearing screening with the techniques discussed above or new ones (like steady state potentials...), combined with CMV and genetic diagnosis in order to solve the limitations inherents to current neonatal programs because CMV and genetic treatment will be a real option [26-29].

\section{Conclusions}


Neonatal hearing screening is a necessary, effective and efficient procedure. All techniques currently available are useful, specific and sensitive, although there are other techniques under development (steady state responses...) and also complemmentary tests (CMV, genetic...) that may improve the current performance of established programs.

It is very important that, if possible, the programs are national in scope and involving primary care, in order to assure measures to control losses in the follow-ups and with post-neonatal audiological protocols for early diagnosis of delayed deafness. And of course, a good communication and implication between the specialists involved is mandatory, ruled by a general coordinator and with a good database to make easy knowing and controlling the quality of the programs, thus justifying the time and money invested.

Author Contributions: Both authors have been involved in conceptualization, writing, preparation, review and editing the original draft.

Funding: This research received no external funding.

Institutional Review Board Statement: Not applicable

Informed Consent Statement: Not applicable

Acknowledgments: To all pediatric department.

Conflicts of Interest: The authors declare no conflict of interest

\section{References}

1. de Yebra M., Libro llamado Refugium infirmorum, muy útil y provechoso para todo genero de gente, en el qual se contienen muchos avisos espirituales para socorro de los afligidos enfermos, y para ayudar a bien morir a los que están en lo ultimo de su vida; con un Alfabeto de $S$. Buenaventura para hablar por la mano.. Madrid. Luys Sanchez. 1593.

2. Oviedo A., El libro "Refugium Infirmorum" (Madrid, 1593), del monje franciscano Fray Melchor de Yebra. Berlin, Clásicos Cultura Sorda, 2007.

3. Bonet J.P., Reduction de las letras y arte para enseñar a ablar a los mudos. [Simplification of the Letters of the Alphabet and Method of Teaching Deaf-Mutes to Speak], Madrid, Francisco Abarca de Angulo. 1620. Fol: 126 and 127.

4. Sequí JM, Mir B, Paredes C, Brines J, Marco J. Resultados preliminares en la aplicación de las otoemisiones acústicas provocadas en el periodo neonatal. An Esp Pediatr 1992; 33(1):73-75.

5. Sequí JM, Mir B, Paredes C, Brines J, Marco J. Resultados de un estudio sobre la presencia de otoemisiones espontáneas en el recién nacido. An Esp Pediatr 1992; 37(2):121-125.

6. Sequí JM, Brines J, Mir B, Paredes C, Marco J. Estudio comparativo entre otoemisiones provocadas y potenciales auditivos tronculares en el periodo neonatal. An Esp Pediatr 1992; 37(6):457-460.

7. Schildroth, A. N., \& Karchmer, M. A. (1986). Deaf children in America, San Diego: College Hill Press

8. Yoshinaga-Itano C, Sedey AL, Coulter DK, Mehl AL. Language of early- and later-identified children with hearing loss. Pediatrics 1998 Nov;102(5):1161-71. doi: 10.1542/peds.102.5.1161.

9. Núñez-Batalla F, Jáudenes-Casaubón C, Sequí-Canet JM, Vivanco-Allende A, Zubicaray-Ugarteche J. "Early diagnosis and treatment of unilateral or asymmetrical hearing loss in children: CODEPEH recommendations". Acta Otorrinolaringol Esp. (Engl Ed) 2020; 71 (1) 45-5. doi: 10.1016/j.otorri.2018.09.004

10. Maxon, A. B., White, K. R., Behrens, T. R., \& Vohr, B. R. Referral rates and cost efficiency in a universal newborn hearing screening program using transient evoked otoacoustic emissions (TEOAE). Journal of the American Academy of Audiology 1995; 6: 217-277.

11. Bubbico L. et al. Evolution of Italian Universal Newborn Hearing Screening Programs. Ann Ig 2017; 29: 116-122 doi:10.7416/ai.2017.2138

12. Sequi Canet JM, Sala Langa MJ, Collar Del Castillo JI. "Resultados de una década de despistaje de hipoacusia en un hospital comarcal." [Results from ten years newborn hearing screening in a secondary hospital]. An Pediatr (Barc). 2016;85:189-196

13. Shang Y, Hao W, Gao Z, Xu C, Ru Y, Ni D. An effective compromise between cost and referral rate: A sequential hearing screening protocol using TEOAEs and AABRs for healthy newborns. Int J Pediatr Otorhinolaryngol. 2016;91:141-145. doi: 10.1016/j.ijporl.2016.10.025.

14. Vos $B$, Lagasse $R$ and Levêque $A$. The organisation of universal newborn hearing screening in the Wallonia-BrusselsFederation. B-ENT, 2013, 9, (Suppl. 21): 9-15

15. Wroblewska-Seniuk, K., Dabrowski, P., Szyfter, W. et al. Universal newborn hearing screening: methods and results, obstacles, and benefits. Pediatr Res 2017; 81: 415-422. 
16. Neumann, K. Euler, H. A. Chadha, S. \& White, K. R. A Survey on the Global Status of Newborn and Infant Hearing Screening. Journal of Early Hearing Detection and Intervention, 2020; 5(2): 63-84.

17. Sequí Canet, J. M; Collar del Castillo, J; Lorente Mayor, L; Oller Prieto, A; Morant Barber, M; Peñalver Giner, O; Valdivieso Martínez, R. Hearing screening based on otoacoustic emissions in infants born in secondary-level hospitals: feasible, efficient and effective. Acta pediatr. esp 2005; 63(11): 465-470,

18. Nuñez F, Jaudenes C, Sequí JM, Vivanco A, Zubicaray J. (CODEPEH). “Actualización de los programas de detección precoz de la sordera infantil:. Nivel 1 detección” Revista Española de Discapacidad 2019; 7: 201-220.

19. Nuñez F, Jaudenes C, Sequí JM, Vivanco A, Zubicaray J. CODEPEH 2014 recommendations for the early detection of delayed hearing loss. An Pediatr (Barc) 2016 Oct;85(4):215.e1-215.e6. doi: 10.1016/j.anpedi.2015.07.010.

20. Nuñez F, Jaudenes C, Sequí JM, Vivanco A, Zubicaray J. Olleta I. Newborn hearing screening programmes in 2020: CODEPEH recommendations. Acta Otorrinolaringol Esp (Engl Ed). 2020 ; 27;S0001-6519(20)30155-2. doi: 10.1016/j.otorri.2020.06.009. Online ahead of print.

21. Moresco BL, Svoboda MD, Ng YT. A Quiet Disease With Loud Manifestations. Semin Pediatr Neurol. 2018;26:88-91

22. Kummer P et al. Potential Benefit of Selective CMV Testing after Failed Newborn Hearing Screening. Int. J. Neonatal Screen. 2018, 4(2), 20;

23. Goderis J, De Leenheer E, Smets K, et al. Hearing loss and congenital CMV infection: a systematic review. Pediatrics. 2014 Nov;134(5):972-82.

24. Sequi-Canet JM, Sala-Langa MJ , Collar Del Castillo JI. Perinatal factors affecting the detection of otoacoustic emissions in vaginally delivered, healthy newborns, during the first 48 hours of life. Acta Otorrinolaringol Esp. 2014;65(1):1-7. doi: 10.1016/j.otorri.2013.07.007.

25. Sequi-Canet JM, Sequi-Sabater JM, Collar-Castillo JI, Orta-Sibu N. Breastfeeding results in better hearing in newborns compared to bottle-feeding. J Clin Transl Res. 2020 Aug 29;6(3):81-86. eCollection 2020 Sep 5.

26. Lu CY, Tsao PN, Ke YY, Lin YH, Lin YH, Hung CC, Su YN, Hsu WC, Hsieh WS, Huang LM, Wu CC, Hsu CJ. Concurrent Hearing, Genetic, and Cytomegalovirus Screening in Newborns, Taiwan. J Pediatr. 2018 Aug;199:144-150.e1. doi: 10.1016/j.jpeds.2018.02.064.

27. Wu C-C, Hung C-C, Lin S-Y, Hsieh W-S, Tsao P-N, et al. (2011) Newborn Genetic Screening for Hearing Impairment: A Pre-liminary Study at a Tertiary Center. PLoS ONE 6(7): e22314. doi:10.1371/journal.pone.0022314

28. Nist-Lund, C.A., Pan, B., Patterson, A. et al. Improved TMC1 gene therapy restores hearing and balance in mice with genetic inner ear disorders. Nat Commun2019; 10: 236. https://doi.org/10.1038/s41467-018-08264-W

29. Adam MP, Ardinger HH, Pagon RA, et al., editors. GeneReviews ${ }^{\circledR}$ [Internet]. Seattle (WA): University of Washington, Seattle; 1993-2021. 